This is the peer reviewed version of the following article:

Francesca Soglia, Giulia Baldi, and Massimiliano Petracci

Effect of the exposure to oxidation andmalondialdehyde on turkey and rabbit meat proteinoxidative stability

JOURNAL OF FOOD SCIENCE Volume 85 issue 10 pp. 3229-3236

which has been published in final form at http://dx.doi.org/10.1111/1750-

3841.15403

This article may be used for non-commercial purposes in accordance with Wiley Terms and Conditions for Use of Self-Archived Versions. 


\title{
Effect of the exposure to oxidation and malondialdehyde on turkey and rabbit meat protein oxidative stability
}

\author{
Francesca Soglia, Giulia Baldi, and Massimiliano Petracci
}

\begin{abstract}
The present study aimed at evaluating the effect of the exposure to a strong oxidative environment (100 $\mathrm{mM}$ $\mathrm{NaClO}$ ) and the concurrent incubation with different malondialdehyde (MDA) concentrations ( 0 to $5 \mathrm{mM}$ ) on protein carbonylation, free thiol groups, total heme pigments, and on the relative concentration of the different myoglobin (Mb) derivatives in turkey thigh and rabbit hind leg meat to elucidate their eventual role in inducing oxidative modifications on the protein fraction. With regard to turkey meat, the addition of a strong oxidant resulted in remarkably higher $(P<$ 0.001) carbonyls along with a reduction in free thiol groups (which become undetectable). The relative concentration of $\mathrm{MbO}_{2}$ and $\mathrm{MetMb}$ was significantly affected $(P<0.001)$ and total heme pigment was reduced by $62 \%$ when fresh meat is compared to its oxidized counterpart. The addition of MDA $2.5 \mathrm{mM}$ (or greater) resulted in a 1.4-fold increase in carbonyls and a tendency $(P=0.07)$ has been observed for free thiol groups whose content decreased as the MDA level increased. Overall, the aforementioned results are in agreement with those obtained on rabbit hind leg meat in which a three-fold increase $(P<0.001)$ in carbonyls and a remarkably higher $(P<0.001)$ MetMb content coupled with a $53 \%$ reduction in free thiol groups were found. No significant differences ascribable to MDA addition were found. In conclusion, exposing turkey and rabbit meat to the same environment resulted in distinctive oxidative changes that might be related to the compositional traits and a species-specific susceptibility of the meat toward oxidation.
\end{abstract}

Keywords: malondialdehyde, meat, oxidation, protein, turkey and rabbit

Practical Application: Protein and lipid oxidation have been investigated in different meat types; nevertheless, the knowledge concerning the interaction between these two phenomena is limited. According to their compositional traits (high PUFA and heme pigment content), turkey and rabbit leg meats are particularly susceptible to oxidation. Providing information concerning the oxidative stability of turkey thigh and rabbit hind leg meat exposed to strong oxidative conditions and to a concurrent increasing content of a secondary product of lipid oxidation, the findings of the present study can be useful when proper processing strategies and storage conditions have to be implemented for manufacturing processed products.

\section{INTRODUCTION}

The oxidative processes affecting protein and lipid in meat and meat products are free radical-mediated chain reactions initiated by the abstraction of a hydrogen atom by reactive oxygen species (ROS) that results in the generation of a protein carbon-centered and a lipid radical, respectively (Estévez, 2011; Guyon, Meynier, \& de Lamballerie, 2016; Lund, Heinonen, Baron, \& Estévez, 2011; Min \& Ahn, 2005). These unstable radicals further react, thus resulting in the development of final oxidation products, which differ depending on the target molecules, as well as on the oxidative conditions (Estévez, 2011). In detail, after exposing the meat to strong oxidative conditions, radicals reacting with proteins and peptides may result in alterations involving both the backbone of the polypeptide chains and the amino acids side chains. Indeed, the cleavage of peptide bonds resulting in protein fragmentation and intermolecular covalent cross-linked derivatives may occur to-

JFDS-2020-0540 Submitted 4/3/2020, Accepted 7/13/2020. Authors are with Department of Agricultural and Food Sciences, University of Bologna, Piazza Goidanich 60, Cesena, FC, 47521, Italy. Direct inquiries to author Petracci (E-mail: m.petracci@unibo.it). gether with the formation of carbonyl groups and hydroperoxides and the loss of cysteine and tyrosine residues (Lund et al., 2011). On the other hand, lipid oxidation results in the development of hydroperoxides, which can further react thus leading to a wide range of secondary products, including pentanal, hexanal, 4hydroxynonenal, and malondialdehyde (MDA) (Fernández, PérezÁlvarez, \& Fernández-López, 1997; Lynch \& Faustman, 2000). Being the main nonmicrobial phenomenon responsible for meat deterioration (as it affects color, texture, flavor, loss of nutritional value, and development of harmful products), lipid oxidation has been extensively studied in meat and meat products (Domínguez et al., 2019). On the other hand, the chemical mechanisms resulting in protein oxidation and its impact on meat quality have raised the attention of the meat scientists later on with the discovery that also the polypeptide chains may undergo oxidative reactions during meat storage and processing. Interestingly, as radicals can be reciprocally transferred between lipids and proteins, lipid-derived ROS and several lipid oxidation products might promote protein oxidation and catalyze the oxidative modifications taking place on their polypeptide chains (Estévez, 2011). Within this context, although the concomitant occurrence of lipid and protein oxidation in meat systems may suggest a possible interaction between these 
two phenomena (Lund et al., 2011), the knowledge concerning the effect of the concomitant exposure to oxidative conditions and secondary products of lipid oxidation on protein oxidative stability is limited. In detail, a recent study evaluated the effect of MDA exposure only on the oxidative stability of the myofibrillar proteins extracted from rabbit meat (Wang, He, Emara, Gan, \& Li, 2019), whereas no information is available on meat as raw material. Although commonly referred to as "white meats," poultry and rabbit leg meats have relatively high PUFA and heme pigment contents, which make them particularly susceptible to the development of oxidative reactions (Hernandez \& Gondret, 2006; Dalle Zotte \& Szendro, 2011; Estévez, 2015; Mercier, Gatellier, Viau, Remignon, \& Renerre, 1998; Petracci \& Cavani, 2013). Recently, the growing interest of both the rabbit and turkey industries in developing processed meat products (Barbut, 2015; Cullere \& Dalle Zotte, 2018; Petracci, Soglia, \& Leroy, 2018; Soglia et al., 2018) shed the light on the need to improve the knowledge concerning the impact of different processing steps (i.e., grinding and cooking) on the oxidative stability of the lipid fraction whose secondary products might promote oxidative modifications on proteins' polypeptide chains and affect their functional and technological properties (Estevez, 2015; Petracci \& Cavani, 2013). Within this context, the present study aimed at evaluating the effect of the exposure to oxidative conditions and the concurrent incubation with different MDA concentrations (from 0 to $5 \mathrm{mM}$ ) on protein carbonylation, free thiol groups, total heme pigments, as well as on the relative concentration of the different myoglobin derivatives in turkey thigh and rabbit hind leg meat in order to elucidate their eventual role in inducing oxidative modifications on the protein fraction.

\section{MATERIALS AND METHODS}

\subsection{Sample preparation}

Five turkey carcasses were collected $24 \mathrm{hr}$ post-mortem from the same flock (BUT BIG 6 hybrid, 100 days-old, average live weight of $9.7 \mathrm{~kg}$ ) farmed, and processed under commercial conditions. After dissection, the Extensor iliotibialis lateralis muscles were finely minced with a grinder and divided into 12 aliquots/each: six to be added with $\mathrm{NaClO}$ to a final concentration of $100 \mathrm{mM}$ (to obtain a strong pro-oxidative environment), whereas the same volume of distilled $\mathrm{H}_{2} \mathrm{O}$ was added to the others (in order to achieve the same dilution of the protein fraction). Then, fresh and oxidized samples were added with different final concentrations of MDA (i.e., $0,0.25,0.5,1.0,2.5$, and $5.0 \mathrm{mM}$ ) and incubated in the dark at $37 \pm 1{ }^{\circ} \mathrm{C}$ for $24 \mathrm{hr}$. No antimicrobial agents were added to the samples in order to inhibit microbial growth. However, the eventual changes in meat quality ascribable to microbial growth during the $24 \mathrm{hr}$ incubation time would definitely be of a lower extent if compared to those related to either the addition of different MDA levels or to the exposure to oxidative conditions, considered as main factors in the present research.

After that, samples were stored at $-80{ }^{\circ} \mathrm{C}$ until analyses carried out to assess the occurrence of protein oxidation, through the quantification of carbonyls and free thiol groups, total heme pigments content, and the relative concentration of the different myoglobin derivatives, such as deoxymyoglobin (DeoxyMb), oxymyoglobin $\left(\mathrm{MbO}_{2}\right)$, and metmyoglobin (MetMb). The same experiment was performed on rabbit hind legs meat by collecting $24 \mathrm{hr}$ post-mortem five carcasses belonging to the same batch (Martini line, 10 weeks old, average live weight of $2.7 \mathrm{~kg}$ ) farmed, and slaughtered in a commercial abattoir. All the muscles belong- ing from this anatomical region were finely minced and samples were prepared and treated as described before.

\subsection{Total heme pigments and myoglobin derivatives}

The concentration of total heme pigments as well as the relative concentration of the different myoglobin derivatives (DeoxyMb, $\mathrm{MbO}_{2}$, and $\mathrm{MetMb}$ ) was determined following the procedure described by Krzywicki (1982) with slight modifications.

Briefly, $2.5 \mathrm{~g}$ of sample was homogenized $(13,500 \mathrm{rpm}$ for 10 s) with an Ultra-Turrax T25 (IKA - WERKE, Labortechnik, Staufen, Germany) in $12.5 \mathrm{~mL}$ of $40 \mathrm{mM}$ phosphate buffer ( $\mathrm{pH}$ 6.8). Following incubation for $1 \mathrm{hr}$ at $4 \pm 1^{\circ} \mathrm{C}$, samples were centrifuged (Beckman Coulter JP-26, Indianapolis, IN, USA) $(15,000$ $\times g$ for $30 \mathrm{~min}$ at $4{ }^{\circ} \mathrm{C}$ ) and the supernatant filtered through filter paper (Whatman 1, GE Healthcare) and through cellulose acetate syringe filter $(20 \mu \mathrm{m})$. Then, the absorbance of the samples was read against blank at $730,525,545,565$, and $572 \mathrm{~nm}$ and total heme pigment as well as the relative concentration of DeoxyMb, $\mathrm{MbO}_{2}$, and $\mathrm{MetMb}$ was calculated as follows, where $\mathrm{R} 1=\mathrm{Abs}$ 572/Abs 525, R2 = Abs 565/Abs 525, and R3 = Abs 545/Abs 525. All the absorbances were corrected taking into account the turbidity of the sample (Abs $730 \mathrm{~nm}$ ).

$$
\begin{aligned}
& \text { Total heme pigments }(\mathrm{mg} \mathrm{Mb} / \mathrm{kg} \text { of meat }) \\
& =\frac{[(0.661 \mathrm{R} 1+0.086 \mathrm{R} 2+0.088 \mathrm{R} 3+0.090) \times \mathrm{Abs} 525] \times 17,500}{\text { sample weight }(\mathrm{g}) \times \text { dilution factor }} \\
& \text { DeoxyMb }(\%)=(0.369 \mathrm{R} 1+1.140 \mathrm{R} 2-0.941 \mathrm{R} 3+0.015) \times 100 \\
& \mathrm{MbO}_{2}(\%)=(0.882 \mathrm{R} 1-1.267 \mathrm{R} 2+0.809 \mathrm{R} 3-0.361) \times 100 \\
& \operatorname{MetMb}(\%)=(-2.541 \mathrm{R} 1+0.777 \mathrm{R} 2+0.800 \mathrm{R} 3+1.098) \times 100
\end{aligned}
$$

\subsection{Carbonyl content}

Protein carbonylation level was assessed in triplicates following the procedure proposed by Levine et al. (1990) and recently modified by Soglia, Petracci, and Ertbjerg (2016). Briefly, $1.0 \mathrm{~g}$ of sample was homogenized $(9,500 \mathrm{rpm}$ for $30 \mathrm{~s})$ in ice by an Ultra-Turrax T25 (IKA - WERKE, Labortechnik). Five aliquots (100 $\mu \mathrm{L} / \mathrm{each})$ of the homogenate were added with $1 \mathrm{~mL} \mathrm{10 \%} \mathrm{TCA.} \mathrm{Following}$ centrifugation $(5,000 \times g$ for $5 \mathrm{~min}$ ) (Beckman Coulter microfuge 16), the supernatant was discarded and $400 \mu \mathrm{L}$ of $5 \%$ sodium dodecyl sulfate (SDS) solution was added to the resulting pellet. The samples were subsequently heated at $100{ }^{\circ} \mathrm{C}$ for $10 \mathrm{~min}$ and ultrasonicated (Argo-lab DU-45, Modena, Italy) at $40{ }^{\circ} \mathrm{C}$ for $30 \mathrm{~min}$. Then, the samples (three replicates) were incubated $(30 \mathrm{~min}$ ) with $800 \mu \mathrm{L}$ of $0.3 \%(\mathrm{w} / \mathrm{v})$ 2,4-Dinitrophenylhydrazine (DNPH) in $3 \mathrm{M} \mathrm{HCl}$, while the same volume of $3 \mathrm{M} \mathrm{HCl}$ was added to the blank (two replicates). Following incubation, $400 \mu \mathrm{L}$ of $40 \%$ TCA was added and the supernatant removed by centrifugation $(5,000 \times g$ for $5 \mathrm{~min})$. The pellet was washed three times with $1 \mathrm{~mL}$ of ethanol-ethyl acetate $(1: 1, \mathrm{v}: \mathrm{v})$ solution by centrifugation at $10,000 \times g$ for $5 \mathrm{~min}$. After the final wash, the pellet was dried, resuspended in $1.5 \mathrm{~mL}$ of $6 \mathrm{M}$ guanidine hydrochloride in $20 \mathrm{mM}$ $\mathrm{NaH}_{2} \mathrm{PO}_{4}(\mathrm{pH} 6.5)$, and the samples were incubated overnight at 4 ${ }^{\circ} \mathrm{C}$. Then, the absorbance at 370 and $280 \mathrm{~nm}$ was measured with a UV-VIS 1800 spectrophotometer (Shimadzu Corporation, Japan) at $25{ }^{\circ} \mathrm{C}$ in order to quantify carbonyls and the protein concentration within the samples, respectively. In detail, carbonyl content, expressed as nmol/mg of protein, was calculated according to the 
equation:

$$
\begin{aligned}
& \text { carbonyl content }(\mathrm{nmol} / \mathrm{mg} \text { of protein }) \\
& =\frac{\operatorname{Abs} 370-\text { Abs } 370(\text { blank })}{22,000 \times[\text { Abs } 280-(\text { Abs } 370-\text { Abs } 370(\text { blank })) \times 0,43]} \times 10^{6}
\end{aligned}
$$

\subsection{Free thiol groups}

Free thiol groups were quantified following their reaction with 5,5'-Dithiobis(2-nitrobenzoic acid) (DTNB) as proposed by Ellman (1959) with some modifications (Lund, Lametsch, Hviid, Jensen, \& Skibsted, 2007). Briefly, $1.0 \mathrm{~g}$ of samples was homogenized $(13,500 \mathrm{rpm}$ for $30 \mathrm{~s})$ with an Ultra-Turrax T25 (IKA WERKE, Labortechnik) in $25 \mathrm{~mL} \mathrm{5 \% (w/v)} \mathrm{SDS} \mathrm{in} 0.1 \mathrm{M}$ Tris$\mathrm{HCl}(\mathrm{pH} 8.0)$. After heating in a water bath at $80^{\circ} \mathrm{C}$ for $30 \mathrm{~min}$, the homogenate was filtered through filter paper (Whatman 1, GE Healthcare) and the protein concentration was assessed by reading the absorbance at $280 \mathrm{~nm}$ and calculated through a standard curve prepared from 0 to $2 \mathrm{mg} / \mathrm{mL}$ bovine serum albumin. Then, free thiol groups were quantified by mixing $0.5 \mathrm{~mL}$ filtrate, $2 \mathrm{~mL}$ of $0.1 \mathrm{M}$ Tris- $\mathrm{HCl}$ (pH 8.0), and $0.5 \mathrm{~mL} 10 \mathrm{mM}$ DTNB in 0.1 $\mathrm{M}$ Tris- $\mathrm{HCl}(\mathrm{pH} 8.0)$ and reading the absorbance of the samples at $412 \mathrm{~nm}$ after $30 \mathrm{~min}$ incubation in the dark. Indeed, forming a disulfide bond with free thiol groups, DTNB releases a thiolate ion with a maximal absorbance at $412 \mathrm{~nm}$ (Estévez, Morcuende, \& Ventanas, 2009). Thiol groups content was calculated by using a standard curve prepared from L-cysteine and expressed as $\mathrm{nmol} / \mathrm{mg}$ protein.

\subsection{Statistical analysis}

Data were analyzed according to a $2 \times 6$ factorial design using the GLM procedure of Statistica (StatSoft Italy srl, Vigonza, Italy). In detail, within the same experiment (turkey and rabbit meat), a factorial ANOVA was performed to investigate the main effects of the exposure to oxidative conditions ( $\mathrm{Ox}$, fresh vs. oxidized) and MDA level (MDA, 0, 0.25, 0.5, 1.0, 2.5, and 5.0 mM) as well as their interaction term "Ox $\times$ MDA" on protein carbonylation, free thiol group, total heme pigments, and on the relative concentration of the different myoglobin derivatives. Mean values were subsequently separated through the parametric Tukey-HSD test. In addition, Student's $t$-test was carried out with the aim to compare protein oxidation and heme pigments in meat belonging from turkey thigh and rabbit hind leg meat without any MDA added and evaluate whether an effect associated with the meat type can be observed. All statistical differences were considered significant at a level of $P \leq 0.05$.

\section{RESULTS AND DISCUSSION}

The results concerning the impact of the exposure to strong oxidative conditions and the concomitant addition of increasing MDA levels on protein oxidation and heme pigments in turkey thigh meat are reported in Table 1.

As expected, the addition of a strong oxidant (100 $\mathrm{mM} \mathrm{NaClO})$ to the system resulted in remarkable oxidative modifications affecting the proteins' polypeptide chains. Indeed, if compared to its fresh counterpart, a significant increase in protein carbonylation ( 3.49 vs. $7.58 \mathrm{nmol} / \mathrm{mg}$ pf protein; $P<0.001$ ) along with a concomitant decrease in free thiol groups was observed in oxidized meat. In detail, free $\mathrm{SH}$ groups became readily undetectable after incubating turkey meat in the presence of $\mathrm{NaClO}$, meaning that the oxidative environment was strong enough to induce oxidation of the cysteine residues. Indeed, following a one- or two-electron oxidation reaction, thiol groups in cysteine can result in the formation of thiyl radicals or sulfenic acids. Because of their unstable nature, these species can further react with other thiol/thiolate to generate disulfide or result in the formation of a disulfide bond, respectively (Zhang, Xiao, \& Ahn, 2013). Thus, the loss of free thiol groups can be considered a reliable marker for protein oxidation (Winther \& Thorpe, 2014) and suggests the occurrence of oxidative modifications in turkey meat involving the formation of disulfide bonds. Overall, this reduction in free thiol groups is in agreement with the findings of previous studies carried out on oxidized myofibrils (Frederiksen, Lund, Andersen, \& Skibsted, 2008; Morzel, Gatellier, Sayd, Renerre, \& Laville, 2006).

As for heme pigments, exposing turkey thigh meat to a strong oxidant significantly affected the content as well as the relative concentration of the oxidized and the oxygenated myoglobin derivatives, whereas the reduced one (DeoxyMb) was not affected $(P$ $>0.05)$. In detail, the content of total heme pigments was found to be decreased by $63 \%$ by comparing fresh meat with its oxidized counterpart (2.04 vs. $0.77 \mathrm{mg} \mathrm{Mb} / \mathrm{kg}$ of meat; $P<0.001)$. This result might be ascribed to a possible damage to the globin molecule that, affecting the stability of the heme group itself, ultimately results in the release of iron (Estévez \& Cava, 2004). The same authors hypothesized a possible relationship between the release of iron from the heme group and the occurrence of protein oxidation, which seems to be in agreement with the results of our study. Concurrently, a $67 \%$ reduction $(P<0.001)$ in the relative concentration of $\mathrm{MbO}_{2}$ matching with a two-fold increase $(P<0.001)$ in the proportion of MetMb was found in oxidized in comparison with fresh meat. Undeniably, the exposure to pro-oxidant conditions can lead to the destabilization of the myoglobin molecule and to a subsequent meat discoloration (Suman \& Joseph, 2013). Indeed, the oxidation of DeoxyMb leads to the formation of MetMb and superoxide that subsequently dismutates to generate $\mathrm{H}_{2} \mathrm{O}_{2}$ and $\mathrm{O}_{2}$ (Chan, Faustman, Yin, \& Decker, 1997). As previously hypothesized by Thiansilakul, Benjakul, and Richards (2011), the $\mathrm{H}_{2} \mathrm{O}_{2}$ thus formed might have induced conformational changes in the globin structure and, affecting myoglobin redox state, ultimately resulted in the release of iron from the porphyrin ring. Intriguingly, it is noteworthy to mention the absence of significant differences in the relative concentration of the reduced pigment form (DeoxyMb). It seems reasonable to hypothesize that this result might be ascribed to the structure of the DeoxyMb molecule itself, in general, and to the absence of ligands at the sixth coordinate of the heme iron in this myoglobin derivative, in particular. Indeed, this may have helped in maintaining the hydrophobic pocket-like structure of the globin thus protecting its heme group from the oxidative environment developed in our experiment.

With regard to the effect of MDA, the achievement of a concentration $2.5 \mathrm{mM}$ (or greater) resulted in a significantly $(P<0.001)$ higher carbonyl content (1.4-fold increase) if compared to the control group (0 mM MDA). This result corroborates the hypothesis that MDA, as a secondary product of lipid oxidation, may trigger an increase in carbonyl groups (Burcham \& Kuhan, 1996; Estévez et al., 2019; Wang et al., 2019), which represents one of the most common consequences of protein oxidation (Estévez, 2011; Lund et al., 2011). However, it is interesting to highlight that, aside from the in-site formation of carbonyl groups following the attack of ROS to the side chain of susceptible amino acids (i.e., proline, lysine, and arginine), protein carbonylation can also result from the addition of secondary preformed carbonyls including those generated from lipid oxidation (among the others, also MDA) (Estévez et al., 2019). Thus, it might be argued whether the increased 


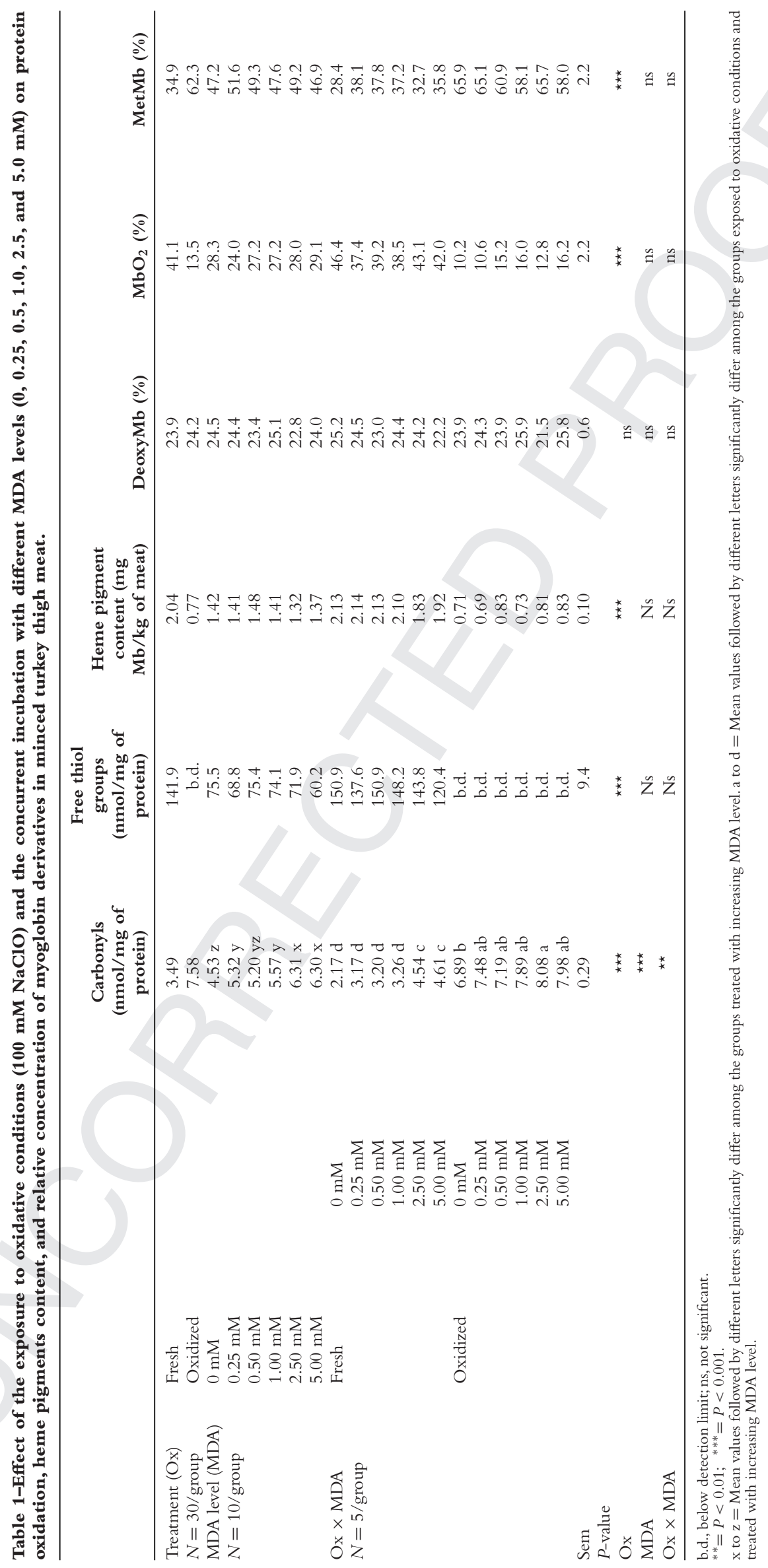


carbonylation level found in association with higher MDA concentration might be attributed to the formation of adducts with this compound rather than to the occurrence of protein oxidation. Having this in mind, in order to get more information concerning the effect of an increasing MDA content on the oxidative damage as well as on the modifications affecting the proteins' structure, free thiol groups were also quantified. Interestingly, a tendency $(P=$ 0.07 ) was observed for free thiol groups whose content was found to decrease as the MDA level added to the system increased. This finding corroborates the hypothesis of the existence of a possible interaction between the aldehydes generated from lipid oxidation and the oxidative modifications affecting proteins' polypeptide chains. In detail, as observed in previous studies, MDA might be involved in the formation of protein aggregates through the generation of cross-linking (Buttkus, 1967; Xiong, Park, \& Ooizumi, 2009). Therefore, it might be speculated that, incubating the samples with increasing MDA levels may have resulted in a conversion of the sulfhydryl groups into disulfide and in the formation of disulfide bonds in the myofibrils thus accounting for the reduction in free thiol groups content. Analogously, a sharp decrease in the sulfhydryl content matching with an increase in the amount of disulfide bonds was previously reported by Liu, Xiong, and Butterfield (2000) in oxidized myofibrillar proteins. At last, the presence of increasing MDA level did not exert any relevant effect on total heme pigments as well as on the relative concentration of the different myoglobin derivatives in turkey meat.

The significant interaction term "Ox $\times$ MDA" observed for carbonyls in turkey meat might be ascribed to the different carbonylation levels observed as a consequence of the increasing MDA concentration in the system and the concurrent exposure to oxidative conditions. In detail, a relevant increase in carbonyl content was found as MDA concentration attained $2.5 \mathrm{mM}$ in both fresh and oxidized meat. However, in the case of fresh meat, a further increase in MDA level (to $5 \mathrm{mM}$ ) led to the same result, whereas an opposite trend was found in oxidized meat in which the highest MDA concentration added to the samples did not result in a significant increase in carbonyls $(P>0.05)$.

Overall, the aforementioned results are in agreement with those obtained for rabbit hind leg meat subjected to the same experimental design, which are reported in Table 2. Exposing rabbit meat to oxidative conditions significantly affected all the parameters considered within this study with the only exception being the relative concentration of DeoxyMb and $\mathrm{MbO}_{2}$ that did not differ between fresh meat and its oxidized counterpart $(P>0.05)$. Indeed, a three-fold increase $(P<0.001)$ in carbonyl content coupled with a one-half reduction $(-53 \% ; P<0.001)$ in free thiol groups was found in oxidized rabbit meat. These findings suggest the occurrence of intense oxidative modifications to the proteins' polypeptide chains. In detail, although it is not clear whether the hydrazones (DNPH-derivatized carbonyls) measured are the result of an in-site formation of carbonyls mediated by ROS or are rather a consequence of adducts with MDA or preformed carbonyl compounds, the remarkable increase in protein carbonylation level associated with a sharp reduction in free thiol groups is considered a good marker of oxidation (Lund et al., 2011). It is noteworthy that the exposure of turkey thigh and rabbit hind leg meat to the same environment affected the protein fraction with a different extent and might have resulted in different oxidative changes. Indeed, if compared to turkey thigh exposed to oxidative conditions, a more intense protein carbonylation seems to take place in rabbit meat (two-fold vs. three-fold increase, in absolute terms) in which, simultaneously, the development of disulfide bonds seems to oc- cur with a lower extent. Indeed, in turkey thigh, free thiol groups became readily undetectable after the exposure to oxidative conditions, whereas a $50 \%$ reduction in their content was found in rabbit hind legs. It might thus be argued whether these distinctive oxidative changes might be related to the compositional traits (i.e., cysteine content, fat content, and fatty acids profile) of the meat considered in the present experiment that might have affected its susceptibility toward oxidation and promoted one oxidative change rather than the other. In addition, a significant reduction in total heme pigments $(0.21$ vs. $0.68 \mathrm{mg} \mathrm{Mb} / \mathrm{kg}$ of meat; $P<0.001)$ associated with an increased proportion of MetMb $(+9 \%)$ was found in rabbit leg meat exposed to oxidative conditions in comparison with the fresh one in agreement with the results observed for turkey thigh meat (Table 1). However, a remarkable difference in the extent of MetMb formation was found, with the increase in the relative concentration of the oxidized pigment form being of about $10 \%$ and $200 \%$ in rabbit and turkey meat, respectively. This finding might suggest a species-specific susceptibility of the myoglobin molecules to oxidation. Indeed, it might be speculated that, because of a higher susceptibility to oxidation, the myoglobin molecules in rabbit meat might have been largely oxidized (i.e., MetMb formed) already during the $24 \mathrm{hr}$ incubation period at $37^{\circ} \mathrm{C}$. The same mechanism might have likely occurred for the lipid fraction, which is relatively high in rabbit meat. Within this context, myoglobin oxidation to MetMb might have been further accelerated by the reactive products of lipid oxidation, which are polar and can readily diffuse within the sarcoplasm (Esterbauer, Schaur, \& Zollner, 1991; Faustman, Liebler, McClure, \& Sun, 1999; Suman \& Joseph, 2013).

The achievement of increasing MDA levels within the system did not exert any relevant effect neither on protein oxidation nor on heme pigments and, similarly, no significant interaction terms "Ox $\times$ MDA" were observed. However, it has to be mentioned that a $25 \%$ reduction in free thiol groups was found by comparing the results obtained in the control group (0 mM MDA) with those observed with the addition of $5 \mathrm{mM}$ MDA. Although not statistically significant, this result corroborates the hypothesis of an MDA-mediated oxidation process involving the development of disulfide bonds.

The results concerning protein oxidation, heme pigments content, as well as the relative concentration of the different myoglobin derivatives found in fresh (without any MDA added, $0 \mathrm{mM}$ ) turkey and rabbit meat, are reported in Table 3. Although no significant differences were found in protein carbonylation level $(P$ $>0.05)$, a significantly higher free thiol groups content was found in rabbit meat in comparison with that observed in turkey matrix (225.0 vs. $150.9 \mathrm{nmol} / \mathrm{mg}$ of protein; $P<0.001)$. Considering that the control groups were also incubated at $37^{\circ} \mathrm{C}$ for 24 $\mathrm{hr}$, these findings corroborate the hypothesis of a species-related development of oxidation products. Indeed, it is likely that part of the free thiol groups in turkey meat has been readily oxidized during the incubation time and the remaining ones were quickly involved in the development of disulfide bonds after the exposure to the oxidative environment (Table 1). Aside from the amino acid composition of the polypeptide chains which vary among species, these results might be ascribed to the exposure to prooxidant compounds, such as hemoproteins (i.e., myoglobin) (Van Dyck, 2010), which are considerably high in turkey meat (Estévez, 2015; Pereira \& Vicente, 2013). In agreement with that, a different susceptibility to oxidation was found in a previous study carried out on meat belonging from different species in which myoglobin was found to be one of the primary determinants for the differ- 


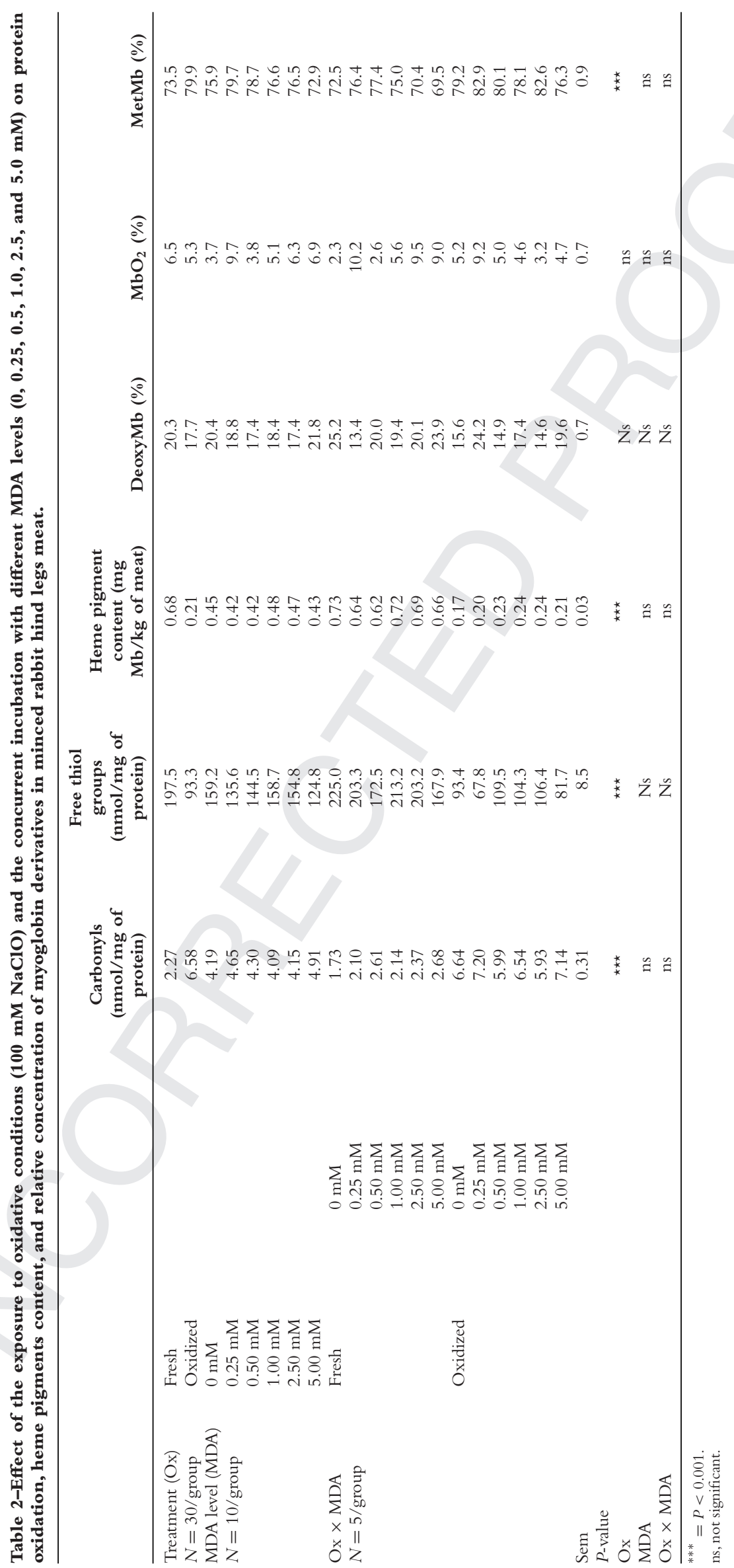


Table 3-Comparison of protein oxidation (carbonyls and free thiol groups), heme pigments content, and relative concentration of myoglobin derivatives in fresh (0 mM MDA) minced turkey thigh and rabbit hind legs meats $(N=5$ samples/group).

\begin{tabular}{|c|c|c|c|c|c|c|}
\hline & $\begin{array}{c}\text { Carbonyls } \\
\text { (nmol/mg of } \\
\text { protein) }\end{array}$ & $\begin{array}{c}\text { Free thiol } \\
\text { groups } \\
\text { (nmol/mg of } \\
\text { protein) }\end{array}$ & $\begin{array}{c}\text { Heme } \\
\text { pigment } \\
\text { content (mg } \\
\text { Mb/kg of } \\
\text { meat) }\end{array}$ & $\begin{array}{c}\text { DeoxyMb } \\
(\%)\end{array}$ & $\mathrm{MbO}_{2}(\%)$ & MetMb (\%) \\
\hline Turkey thigh & 2.17 & 150.9 & 2.13 & 25.2 & 46.4 & 28.4 \\
\hline $\begin{array}{l}\text { Rabbit hind } \\
\text { leg }\end{array}$ & 1.73 & 225.0 & 0.73 & 25.2 & 2.3 & 72.5 \\
\hline Sem & 0.22 & 7.2 & 0.07 & 0.5 & 1.5 & 1.8 \\
\hline$P$-value & Ns & $\star \star \star$ & $\star \star \star$ & ns & $\star \star \star \star$ & $\star \star \star \star$ \\
\hline
\end{tabular}

*** $P<0.001$

ns, not significant.

ences in oxidative stability of meat (Min, Nam, Cordray, \& Ahn, 2008). With regard to heme pigments, if compared to rabbit hind leg meat, turkey thigh matrix exhibited a significantly higher total heme and $\mathrm{MbO}_{2}$ content along with a significantly lower proportion of MetMb. On the other hand, no significant differences were found in the relative concentration of DeoxyMb. The significantly lower heme pigment content observed in rabbit hind leg in comparison with turkey thigh meat might be a consequence of a partial release of iron from the heme group (discoloration) taking place during the $24 \mathrm{hr}$ incubation time at $37^{\circ} \mathrm{C}$. In addition, as lipid oxidation proceed fast, the higher lipid content in rabbit hind leg meat may have resulted in a more intense development of aldehydes that, forming adducts with the histidine residue in myoglobin, can strongly affect color stability (Suman \& Joseph, 2013). On the other hand, the remarkable differences in $\mathrm{MbO}_{2}$ and MetMb might be explained by considering the different susceptibility of avian and mammalian myoglobin to oxidation hypothesized by Yin et al. (2011). Though myoglobin functions are among the highly conserved traits across poultry and livestock species, its primary structure, ultimately affecting the interactions with other molecules, profoundly differs (Suman \& Joseph, 2013). Indeed, the presence of negatively charged residues was previously found to affect buffalo myoglobin stability whose meat resulted more prone to discoloration (Dosi et al., 2006). In addition, also the number of histidine residues, favorable target for the adduction of aldehydes generated by lipid oxidation, was also hypothesized to contribute to myoglobin susceptibility to oxidation (Suman \& Joseph, 2013). Thus, within this context, the differences in $\mathrm{MbO}_{2}$ and MetMb observed between turkey thigh and rabbit hind leg meat are likely ascribable to the unique primary structure of their myoglobin molecules.

\section{CONCLUSION}

The findings of the present study suggest the occurrence of species-specific oxidative changes affecting proteins polypeptide chains in different meat types. These may partly be attributed to the different susceptibility to oxidation of the myoglobin molecules belonging to different species that should thus be carefully considered and requires the implementation of processing strategies aiming at minimizing the occurrence of meat discoloration or, at least, reduce its impact on consumers' acceptability. In addition, as the occurrence of oxidative reactions strongly depends on the meat-cut taken into account but is also influenced by each processing step and the storage conditions as well, these aspects need to be surely considered when developing further processed products with the inclusion of turkey and rabbit meats.

\section{AUTHOR CONTRIBUTIONS}

Francesca Soglia and Massimiliano Petracci were responsible for study conception and design. Francesca Soglia and Giulia Baldi performed the analyses and interpreted the results. All the authors contributed to draft the manuscript and critically revised it.

\section{CONFLICTS OF INTEREST}

No conflicts of interest to declare.

\section{REFERENCES}

Barbut, S. (2015). Developments in turkey meat harvesting technologies. World's Poultry Science Journal, 71, 59-70.

Burcham, P. C., \& Kuhan, Y. T. (1996). Introduction of carbonyl groups into proteins by the lipid peroxidation product, malondialdehyde. Biochemical and Biophysical Research Communications, 220(3), 996-1001. https://doi.org/10.1006/bbrc.1996.0521

Buttkus, H. (1967). The reaction of myosin with malonaldehyde. Journal of Food Science, 32(4), 432-434. https://doi.org/10.1111/j.1365-2621.1967.tb09703.x

Chan, W. K. M., Faustman, C., Yin, M., \& Decker, E. A. (1997). Lipid oxidation induced by oxymyoglobin and metmyoglobin with involvement of $\mathrm{H}_{2} \mathrm{O}_{2}$ and superoxide anion. Meat Science, 46(2), 181-190. https://doi.org/10.1016/S0309-1740(97)00014-4

Cullere, M., \& Dalle Zotte, A. (2018). Rabbit meat production and consumption: State of knowledge and future perspectives. Meat Science, 143, 137-146. https://doi.org/10.1016/j.meatsci. 2018.04.029

Dalle Zotte, A., \& Szendro, Z. (2011). The role of rabbit meat as functional food. Meat Science, 88(3), 319-331. https://doi.org/10.1016/j.meatsci.2011.02.017

Domínguez, R., Pateiro, M., Gagaoua, M., Barba, F. J., Zhang, W., \& Lorenzo, J. M. (2019). A comprehensive review on lipid oxidation in meat and meat products. Antioxidants, 8(10), 1-31. https://doi.org/10.3390/antiox8100429

Dosi, R., Di Maro, A., Chambery, A., Colonna, G., Costantini, S., Geraci, G., \& Parente, A. (2006). Characterization and kinetics studies of water buffalo (Bubalus bubalis) myoglobin. Comparative Biochemistry and Physiology - Biochemistry and Molecular Biology, 145(2), 230-238. https://doi. org/10.1016/j.cbpb.2006.07.006

Ellman, G. L. (1959). Tissue sulfhydryl groups. Archives of Biochemistry and Biophysics, 82(1), 70-77. https://doi.org/10.1016/0003-9861(59)90090-6

Esterbauer, H., Schaur, R. J., \& Zollner, H. (1991). Chemistry and biochemistry of 4hydroxynonenal, malonaldehyde and related aldehydes. Free Radical Biology and Medicine, 11, 81-128.

Estévez, M. (2011). Protein carbonyls in meat systems: A review. Meat Science, 89(3), 259-279. https://doi.org/10.1016/j.meatsci.2011.04.025

Estévez, M. (2015). Oxidative damage to poultry: From farm to fork. Poultry Science, 94(6), 13681378. https://doi.org/10.3382/PS/PEV094

Estévez, M., \& Cava, R. (2004). Lipid and protein oxidation, release of iron from heme molecule and colour deterioration during refrigerated storage of liver pâté. Meat Science, 68(4), 551-558. https://doi.org/10.1016/j.meatsci.2004.05.007

Estévez, M., Morcuende, D., \& Ventanas, S. (2009). Determination of oxidation. In L. M. L. Nollet \& F. Toldrá (Eds.), Handbook of muscle foods analysis (pp. 141-163). Boca Raton, FL: CRC Press.

Estévez, M., Padilla, P., Carvalho, L., Martín, L., Carrapiso, A., \& Delgado, J. (2019). Malondialdehyde interferes with the formation and detection of primary carbonyls in oxidized proteins. Redox Biology, 26(April), 101277. https://doi.org/10.1016/j.redox.2019.101277

Faustman, C., Liebler, D. C., McClure, T. D., \& Sun, Q. (1999). $\alpha, \beta$-Unsaturated aldehydes accelerate oxymyoglobin oxidation. Journal of Agricultural and Food Chemistry, 47(8), 3140-3144. https://doi.org/10.1021/jf990016c

Fernández, J., Pérez-Álvarez, J. A., \& Fernández-López, J. A. (1997). Thiobarbituric acid test for monitoring lipid oxidation in meat. Food Chemistry, 59(3), 345-353. https://doi.org/10.1016/ S0308-8146(96)00114-8

Frederiksen, A. M., Lund, M. N., Andersen, M. L., \& Skibsted, L. H. (2008). Oxidation of porcine myosin by hypervalent myoglobin: The role of thiol groups. Journal of Agricultural and Food Chemistry, 56(9), 3297-3304. https://doi.org/10.1021/jf072852p

Guyon, C., Meynier, A., \& de Lamballerie, M. (2016). Protein and lipid oxidation in meat: A review with emphasis on high-pressure treatments. Trends in Food Science and Technology, 50, 131-143. https://doi.org/10.1016/j.tifs.2016.01.026 
Krzywicki, K. (1982). The determination of haem pigments in meat. Meat Science, 7(1), 29-36. https://doi.org/10.1016/0309-1740(82)90095-X

Levine, R. L., Garland, D., Oliver, C. N., Amici, A., Climent, I., Lenz, A. G., ... Stadtman, E. R. (1990). Determination of carbonyl content in oxidatively modified proteins. Methods in Enzymology, 186(C), 464-478. https://doi.org/10.1016/0076-6879(90)86141-H

Liu, G., Xiong, Y. L., \& Butterfield, D. A. (2000). Properties of oxidized myofibrils and whey- and soy-protein isolates. Journal of Food Science, 65(5), 811-818.

Lund, M. N., Heinonen, M., Baron, C. P., \& Estévez, M. (2011). Protein oxidation in muscle foods: A review. Molecular Nutrition and Food Research, 55(1), 83-95. https://doi.org/10.1002/mnfr. 201000453

Lund, M. N., Lametsch, R., Hviid, M. S., Jensen, O. N., \& Skibsted, L. H. (2007). High-oxygen packaging atmosphere influences protein oxidation and tenderness of porcine longissimus dors during chill storage. Meat Science, 77(3), 295-303. https://doi.org/10.1016/j.meatsci.2007.03 016

Lynch, M. P., \& Faustman, C. (2000). Effect of aldehyde lipid oxidation products on myoglobin. Journal of Agricultural and Food Chemistry, 48(3), 600-604. https://doi.org/10.1021/j9990732e Mercier, Y., Gatellier, P., Viau, M., Remignon, H., \& Renerre, M. (1998). Effect of dietary fat and vitamin $\mathrm{E}$ on colour stability and on lipid and protein oxidation in turkey meat during storage. Meat Science, 48(3-4), 301-318. https://doi.org/10.1016/s0309-1740(97)00113-7

Min, B., \& Ahn, D. U. (2005). Mechanism of lipid peroxidation in meat and meat products - A review. Food Science and Biotechnology, 14(1), 152-163.

Min, B., Nam, K. C., Cordray, J., \& Ahn, D. U. (2008). Endogenous factors affecting oxidative stability of beef loin, pork poin, and chicken breast and thigh meats. Journal of Food Science, 73(6), C439-C446. https://doi.org/10.1111/j.1750-3841.2008.00805.x

Morzel, M., Gatellier, P., Sayd, T., Renerre, M., \& Laville, E. (2006). Chemical oxidation decrease proteolytic susceptibility of skeletal muscle myofibrillar proteins. Meat Science, 73(3), 536-543. https://doi.org/10.1016/j.meatsci.2006.02.005

Pereira, P. M. de C. C., \& Vicente, A. F. dos R.B. (2013). Meat nutritional composition and nutritive role in the human diet. Meat Science, 93(3), 586-592. https://doi.org/10.1016/j.meatsci.2012. 09.018

Petracci, M., \& Cavani, C. (2013). Rabbit meat processing: Historical perspective to future directions. World Rabbit Science, 21(4), 217-226. https://doi.org/10.4995/wrs.2013.1329
Petracci, M., Soglia, F., \& Leroy, F. (2018). Rabbit meat in need of a hat-trick: From tradition to innovation (and back). Meat Science, 146, 93-100. https://doi.org/10.1016/J.MEATSCI.2018. 08.003

Soglia, F., Baldi, G., Laghi, L., Mudalal, S., Cavani, C., \& Petracci, M. (2018). Effect of white striping on turkey breast meat quality. Animal, 12(10), 2198-2204. https://doi.org/10.1017/ S1751731117003469

Soglia, F, Petracci, M., \& Ertbjerg, P. (2016). Novel DNPH-based method for determination of protein carbonylation in muscle and meat. Food Chemistry, 197, 670-675. https://doi.org/10. 1016/j.foodchem.2015.11.038

Suman, S. P., \& Joseph, P. (2013). Myoglobin chemistry and meat color. Annual Review of Food Science and Technology, 4(1), 79-99. https://doi.org/10.1146/annurev-food-030212-182623

Thiansilakul, Y., Benjakul, S. \& Richards, M. P. (2011). The effect of Fenton's reactants and aldehydes on the changes of myoglobin from Eastern little tuna (Euthynnus affinis) dark muscle. European Food Research and Technology, 232(2), 221-230. https://doi.org/10.1007/s00217-010$1370-z$

Van Dyck, S. (2010). The impact of singlet oxygen on lipid oxidation in foods. In Oxidation in foods and beverages and antioxidant applications: Understanding mechanisms of oxidation and antioxidant activity (pp. 57-75). Elsevier Inc.

Wang, Z., He, Z., Emara, A. M., Gan, X., \& Li, H. (2019). Effects of malondialdehyde as a byproduct of lipid oxidation on protein oxidation in rabbit meat. Food Chemistry, 288, 405-412. https: //doi.org/10.1016/j.foodchem.2019.02.126

Winther,J.R., \& Thorpe, C. (2014). Quantification of thiols and disulfides. Biochimica et Biophysica Acta - General Subjects, 1840(2), 838-846. https://doi.org/10.1016/j.bbagen.2013.03.031

Xiong, Y. L., Park, D., \& Ooizumi, T. (2009). Variation in the cross-linking pattern of porcine myofibrillar protein exposed to three oxidative environments. Journal of Agricultural and Food Chemistry, 57(1), 153-159. https://doi.org/10.1021/j88024453

Yin, S., Faustman, C., Tatiyaborworntham, N., Ramanathan, R., Maheswarappa, N. B, Mancini, R. A., ... Sun, Q. (2011). Species-specific myoglobin oxidation. Journal of Agricultural and Food Chemistry, 59(22), 12198-12203. https://doi.org/10.1021/jf202844t

Zhang, W., Xiao, S., \& Ahn, D. U. (2013). Protein oxidation: Basic principles and implications for meat quality. Critical Reviews in Food Science and Nutrition, 53(11),1191-1201. https://doi.org/ $10.1080 / 10408398.2011 .577540$

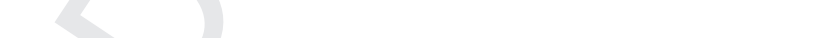

